\title{
¿Es "Don Segundo Sombra" novela picaresca?
}

Muy poco común ha sido la suerte de Don Segundo Sombra, obra maestra de Ricardo Güiraldes reconocida como tal desde el momento de su aparición, (I) y cuya calidad de novela que marca época en las letras del continente no hay nadie que la ponga en tela de juicio. Ya en esta fecha, transcurridos unos doce años, se le puede profetizar un porvenir de clásico indiscutible, pronóstico concedido a contadísimos libros. Quizás convenga, pues, detenernos a examinar las bases de su preeminencia con una serenidad imposible en los primeros instantes de caluroso entusiasmo, limitándonos por ahora a algunas consideraciones - acaso excesivamente vagas- sobre la fórmula novelística que encarna la obra.

Con admirable penetración echó de ver Waldo Frank el parecido esencial entre Don Segundo Sombra y The Adventures of Huckleberry Finn del no siempre bien llanado humorista Mark Twain. (2) Ahora bien, Huckleberry Finn, obra ya clásica y consagrada por dos generaciones de lectores, es universalmente admitido como maravilloso ejemplo de la novela picaresca. (3) Luego ¿ es que en Don Segundo Sombra tenemos otro ejemplo de tan castizo género? Antes de dar una contestación veamos como punto de partida las bases de la inclusión de la novela norteamericana dentro del tipo picaresco. Presenta ésta 
la autobiografía de un muchacho desvalido, de origen obscuro, que, rozándose con los abigarrados pobladores de la frontera, y teniendo que aguzar el ingenio para vivir por las malas cuando no por las buenas, nos pinta no solamente las aventuras y los cuadros clásicos de la vida fronteriza aludidos por Frank, (4) sino además actitudes e impresiones de índole picaresca. Es decir, reúne el pícaro y lo picaresco, (5) que son los primeros requisitos.

Ortega y Gasset escribe que "la novela picaresca echa mano de un figurón nacido en las capas inferiores de la sociedad... y le hace mozo de muchos amos... Este personaje mira la sociedad de abajo arriba ridículamente escorzada, y una tras otra las categorías sociales, los ministerios, los oficios se van desmoronando, y vamos viendo que por dentro no eran más que miseria, farsa, vanidad, empaque e intriga". (6) Anádase que la novela picaresca por excelencia también tiene que ser autobiografía: "Deux procédés ont concouru a la formation de ce genre où les Espagnols ont excellé: le récit autobiographique et la satire des moeurs contemporaines". (7) Luego son esenciales el que se ha llamado antihéroe y la observación realista, especialmente de un realismo pesimista y cínico. Y Huckleberry Finn no está mal catalogado dentro del género, no obstante -e importa hacer hincapié en esto- cierto humorismo y sentido de la naturaleza no completamente propios al pícaro. (8)

Prosiguiendo la comparación, Don Segundo Sombra también es autobiografía de un muchacho si no enteramente desamparado, al menos de origen dudoso, y despejado con ese despejo no exento de amargura, de granuja que hace reír y se da maña para que le den cuartos. Conoce el supuesto narrador al que va a ser su padrino, y siguen los años de "mozo de muchos amos" que dan ocasión para las observàciones de diversas 'fases de la vida pampera, entre ellas algunas de fuerte sabor picaresco: riña de gallos, carrera de caballos... Lenguaje e incidentes, todo es realista, gran parte de ello picaresco, y escri- 
to en forma de autobiografía del consabido picartuelo; además, lo deshilvanado de esa serie de capítulos constituye un distintivo casi universal del género. Porque a pesar de cierta unidad superior a la de la mayoría de las novelas picarescas, unidad debida en parte al relieve de la figura de don Segundo, y en parte más aparente que real, no sabemos por qué magia del autor, muchos episodios, singularmente los cuentos interpolados por don Segundo, podrían sustraerse fácilmente, no diremos que sin perder el libro, pero sí sin perjudicar grandemente a la forma. $\mathrm{Y}$ sin embargo ¿es novela picaresca Don Segundo Sombra? Falta saber hasta qué punto se admiten en las novelas del género elementos de idealismo. Nada, por cierto, más esencial a este libro que el idealismo que respira, ni nada menos picaresco: primero, el profundo respeto y cariño que se tributan ahijado y padrino, $y$ luego, y de importancia no menos trascendental, ese ambiente amoroso de delicada melancolía varonil que envuelve paisaje y escenas, nota de tanto más efecto cuanto menos manifiesta e insistente.

Hemos señalado ya, en Huckleberry Finn, la presencia de elementos cuya propiedad es por lo menos muy discutible en una novela picaresca, y nadie, sin embargo, discute la clasificación del libro dentro del tipo. En situación paralela está $L a-$ zarillo de Tormes: "Suele mirarse el Lazarillo de Tormes como la primer manifestación del género picaresco", dice Américo Castro. "Es exacto, aunque debe tenerse presente un matiz importante: que el Lazarillo... encierra al mismo tiempo gérmenes de una visión de la vida más compleja que la adoptada por las obras clásicas de ese género... La figura del Escudero, algunos aspectos de Lázaro hacen presentir... algo del maravilloso dualismo Don Quijote-Sancho". (9) ¿Hasta dónde son admisibles tales elementos sin quitar a una novela su derecho de entrada al género? El mismo Castro se muestra muy inflexible sobre el punto: en la novela picaresca "son esenciales la técnica naturalista, el carácter autobiográfico y gustar la vida 
con mal sabor de boca. Si al decir novela picaresca pensamos otra cosa, nos salimos de la correspondiente categoría estética e histórica; y en la medida que un autor se aleje de ese esquema, se alejará tạmbién del concepto de novela picaresca". (Io) $\mathrm{Y}$ niega Castro que El coloquio de los perros, generalmente considerado novela picaresca, pertenezca al género: "Si por su carácter autobiográfico la genial novelita recuerda la traza de la novela picaresca, la analogía no pasa de la superficie..." Según este juicio, no es ni puede ser tampoco Don Segundo Sombra novela picaresca. Pero otros críticos conceden mayor amplitud, en la práctica cuando no en las definiciones. Por ejemplo, en el estudio arriba citado (12) dice Ortega y Gasset que "Baroja prolonga una tradición muy honda de nuestra literatura", verbigracia la de "componer novelas que son del género picaresco". Estas palabras las dice refiriéndose en primer lugar a "esta crítica de las costumbres, esta flagelación de la sociedad", pero no vacila en admitir otros elementos. Así juzga que "los libros de Baroja representan un compromiso entre el puro apicaramiento y unos fuertes ímpetus... de aspiración a cosas mejores". ( I3) Y con esto ya ensancha bastante los límites. Dice, además, que "el héroe de Baroja es el vagabundo... El vagabundo es una mixtura del pícaro y del idealista. Pero aunque se componga de ambos simples, es, primero y más hondamente que pícaro, idealista... El vagabundo no vaga por el mundo por motivos externos; no es un fracasado... Vaga por genialidad..." (pág. 378). No cabe definición más exacta del personaje de Güiraldes, aunque claro es que en éste el idealismo es más cosa de la emoción que de la razón.

De todos modos, descle uno y otro punto de vista, el estrecho de Castro y el amplio de Ortega, resulta que una de las bases del arte de Güiraldes en Don Segundo Sombra es la utilización de la fórmula picaresca. Si consideramos que lo más esencial de esta fórmula es la parte externa, la estructura, y que puede variar dentro de muy grandes límites el contenido ideal; 
se puede decir que Don Segundo Sombra es novela picaresca sin modificar el calificativo. Y si insistimos en la actitud corrosiva, el mal sabor de boca que faltan en este libro, no lo es más que a medias. E1 molde seguiría siendo el de la novela picaresca, aunque la materia vertida en él se considerase extraña a tal género. En todo caso, mucho le debe Güiraldes a la castiza forma picaresca, pero a Güiraldes le debe más ella. Porque él la ha revivificado con aliento creador, la ha hecho en cierto modo símbolo de todo lo hispano en tierra de América. viendo por viejos cristales nuevos paisajes y nuevos derroteros

\section{EDWIN S. MORBY.}

(1).-Es interesante notar el juicio que expresaba Valéry Larbaud sobre Güiraldes allá por I920: "Ricardo Güiraldes est un des premiers, et peut-être le premier, parmi les poètes de la plus récente génération littéraire de la République Argentine", juicio que reviste todos los caracteres vaticinio; y por si parece poco, véase lo que dice sobre Gabriel Miró, tampoco adecuadamente apreciado en aquel entonces. Poètes Espagnols et HispanoAméricains contemporains", Nouvelle Revue Française xv, I920, I4I-I47.

(2).--Introducción a la traducción inglesa de la novela de Güiraldes hecha por Harriet de Onís, New York, Farrar and Rinehart, 1935.

(3).-. "Huckleberry Finn, a picaresque romance worthy to rank with the very best examples of picaresque fiction", Archibald Henderson, Mark Twain, New York, I9I2, pág. I75; "The title announces the structure: a picaresque novel...", Bernard de Voto, Mark Twain's America, Boston, 1932, pág. $3^{1} 3$. Podrían irse amontonando las citas.

(4).-But the books are a great deal more than good adventure stories, being classic pictures of the traditions and ideas, the institutions and the folk of the two countries", loc. cit., pág. ix. Compárese: "Das Abenteuerleben der Knaben genügte ihm nicht, so schilderte er im Zusammenhang damit die ganze Zivilisation, die diese Jugend umgab", Friedrich Schönemann, Mark Treain als literarische Persönlichkeit, Jena, 1925, pág. 47.

(5).-Importa hacer una distinción clara y bien delineada. La Celestina, por ejemplo, puede citarse como novela (o drama, si se quiere) que ofrece soberbios cuadros picarescos, sin que por eso, faltándole, no pícaros, sino el picaro, pueda llamarse novela picaresca. Lo propio se puede decir de muchos capítulos de Cervantes. Véanse sobre el particular en El pensa- 
miento de Cervantes, por Américo Castro, Madrid, 1925, las páginas que tendremos ocasión de citar más adelante. Castro niega rotundamente que Cervantes haya escrito, ni que hubiera encontrado posible escribir, novela picaresca. Véanse también las tảblas de la introducción a la traducción inglesa de La Celestina, Broadway Translations, London-New York, ed. H. Warner Allen, s. a., que por la estrecha relación que existe entre el desarrollo de la novela picaresca y el del realismo en general dan entrada a muchísimas obras que poco o casi nada tienen que ver con el género.

(6).- “Observaciones de un lector", La lectura, xv: 3, 1915, p. 376.

(7).-A. Morel-Fatio, prefacio a la Vie de Lazarille de Tormès, París, 1886, pág. ii. Compárese, "The novela picaresca is the autobiography or a pícaro, a rogue, and in that form a satire upon the conditions and persons of the time that gives it birth", Fonger de Haan, An Outline of the History of the novela picaresca in Spain, The Hague-New York, 1903. Esta es la definición más estricta. Otras autoridades admiten límites algo más anchos. Por ejemplo, ya que hemos tocado el punto, la forma autobiográfica no es imprescindible para todos; además de Ortega y Gasset, véanse Mérimée-Morley, A. Hist. of Span. Lit., New York, 1930, pág. 202 y la nota correspondiente; H. Warner Allen, loc. cit., pág. xxi; y A. Valbuena Prat. Hist. de la lit. esp., dos tomos, Barcelona, I937, I, pág. 429.

(8).-Stuart P. Sherman, en The Cambridge Hist. of American Lit., cap. VIII.

(9).-Op. cit., pág. 233.

(10).-Ibid., pág. 234 .

(II).-Y añadamos que por el motivo de los "muchos amos" y otros numerosos aspectos del contenido. La cita es de la página 238.

(12).-Pág. 373 .

( I3).-Ibid, pág. 377 . 